\title{
Characterization and Performance Evaluation of Advanced Aircraft Electric Power Systems
}

\author{
Ahmad Eid ${ }^{\dagger}$, Hassan El-Kishky*, Mazen Abdel-Salam**, and Mohamed T. El-Mohandes*** \\ $\dagger * * *$ Dept. of Electrical Eng., South Valley University, Aswan, Egypt \\ ${ }^{*}$ Dept. of Electrical Eng., University of Texas at Tyler, Texas, USA \\ ** Dept. of Electrical Eng., Assiut University, Assiut, Egypt
}

\begin{abstract}
A model of an advanced aircraft electric power system is developed and studied under variable-speed constant-frequency (VSCF) operation. The frequency of the generator's output voltage is varied from $400-\mathrm{Hz}$ to $800-\mathrm{Hz}$ for different loading scenarios. Power conversions are obtained using 12-pulse power converters. To reduce the harmonic contents of the generator output waveforms, two high-pass passive filters are designed and installed one at a time at the generator terminals. The performance of the two passive filters is compared according to their losses and effectiveness. The power quality characteristics of the studied VSCF aircraft electric power system are presented and the effectiveness of the proposed filter is demonstrated through compliance with the newly published aircraft electrical standards MIL-STD-704F.
\end{abstract}

Key Words: Aircraft electric power system, High-pass filters, Power quality, THD, Variable-speed constant-frequency

\section{INTRODUCTION}

Conventional civil aircraft architecture consists of a combination of systems dependent on mechanical, pneumatic, hydraulic and electrical sources. These systems have drawbacks such as low efficiency, difficulty in detecting leaks regarding the pneumatic system, using many gearboxes for mechanical systems, heavy inflexible piping and the potential leakage of dangerous and corrosive fluids for the hydraulic system. Electrical power is very flexible and doesn't require a heavy infrastructure. Its major drawbacks are a lower power density than hydraulic power and a higher risk of fire in the case of a short circuit [1].

The trend is to move towards more/all electric (advanced) aircraft which means that all of the power off-takes from the aircraft are electrical in nature. This requires a highly reliable, fault tolerant, autonomously controlled electrical power system to deliver higher quality power levels to the aircraft's loads. It has been found [2] that aircraft with more electric systems reduce fuel consumption and improve reliability as a result of fault-tolerant electric power distribution, flight control actuators and the elimination of the hydraulic system. Other benefits of advanced aircraft system are reduced design complexity, lower flight test hours, less tooling, shorter checkout time and elimination/reduction of the hydraulic system which has an

\footnotetext{
Manuscript received Sep. 11, 2009; revised Jul. 10, 2010

$\dagger$ Corresponding Author: ahmadeid@ieee.org

Tel: +2-097-466-1406, Fax: +2-097-466-1406, South Valley Univ.

* Dept. of Electrical Eng., University of Texas at Tyler, USA

** Dept. of Electrical Eng., Assiut University, Egypt

*** Dept. of Electrical Eng., South Valley University, Egypt
}

impact on the environment. Regarding the generating system of the aircraft there are three systems; the constant speed drive (CSD) [3], the integrated drive generator (IDG) [3], [4] and the variable-speed constant-frequency (VSCF) generating system [5].

The VSCF electrical system is more flexible than the CSD/IDG systems since its components can be distributed throughout the aircraft, in contrast to the CSD/IDG where the mechanical systems are located close to the engine. Furthermore, any electrical component can be replaced whenever failure occurs and thus the maintenance of the VSCF system is easier [5].

In aircraft electric power systems, DC power is needed and hence rectification is necessary. The rectification devices are either passive (diode) rectifiers or active elements (switches). Both rectifier circuits generate harmonics at the generator terminals which lessen the performance of the generator. The harmonics in the aircraft electric power systems are studied and eliminated using passive filters [6], [7] or active filters [8].

In this paper a complete simulation model for an advanced aircraft electric power system is investigated under the VSCF generating system. The output power of the aircraft system is equivalent to a Boeing 767's power of 90-kVA per channel. In this model, different load combinations are adopted including passive and dynamic AC loads as well as DC loads. The DC loads are constant power, constant current and constant voltage loads. Two high-pass filters (HPF); first-order and secondorder filters, are designed and installed one at a time at the generator terminals to reduce the harmonics generated from 


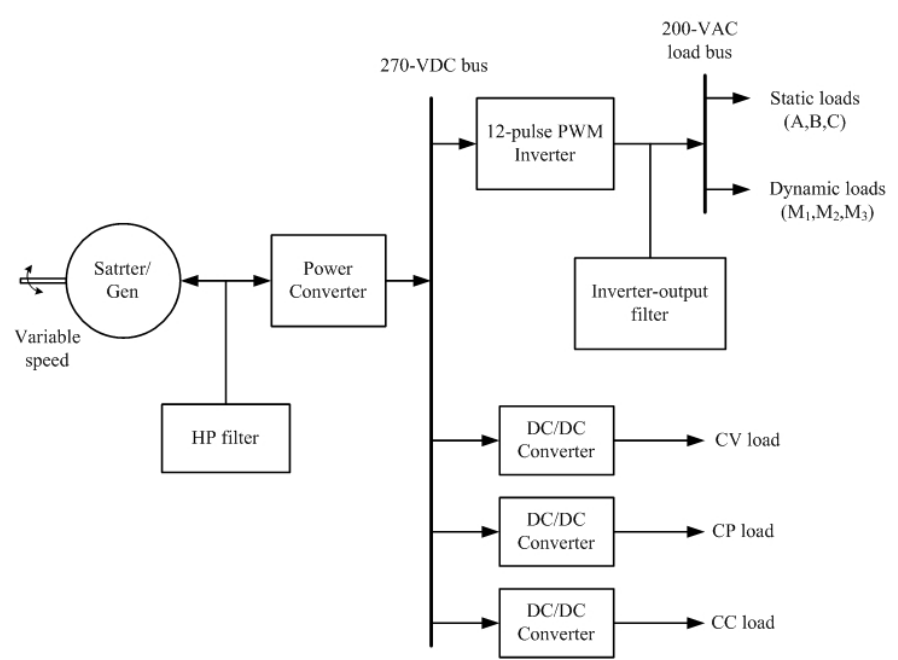

Fig. 1. Advanced aircraft electric power system structure.

the used power conversion units.

\section{COMPONENTS OF AIRCRAFT POWER SYSTEM}

The electric power system of an advanced aircraft includes an internal combustion engine, electric starters/generators, integrated power units, solid-state power controllers, electricdriven flight actuators, an electric anti-icing system, a faulttolerant solid state electrical distribution system, electric aircraft utility functions, and electric-driven environmental and engine controllers. A simplified block diagram of the electric power system of an advanced aircraft channel [9], is shown in Fig. 1. During the starting mode, the battery (or the ground power) system provides power, through the interface power converter, to the electric machine which acts as a starter for the aircraft engine.

In the generating mode, a variable speed engine provides input power to the generator. The generator output is then delivered via the interface converter to the constant frequency system. The synchronous generator output voltage has a 400to $800-\mathrm{Hz}$ frequency range [10]. The parameters and constants of the synchronous generator have been previously reported [10]. The power converter used in an aircraft is either a passive 6-pulse [4], an active 6-pulse [2] or a passive 12-pulse [7] configuration.

In this study, a passive 12-pulse transformer rectifier unit (TRU), as shown in Fig. 2, is used in order to eliminate the low frequency input current harmonics of the synchronous generator. The TRU provides an inherent high power factor and a low total harmonic distortion (THD) of $13 \%$ [2]. No switching is required for the rectifier and hence the losses are reduced. Moreover, the diodes are normally very robust. A three-phase Y/Y/D transformer, see Fig. 2, provides the necessary phase shift for 12-pulse operation. The output voltage of the TRU (270-VDC) is regulated by controlling the field current of the synchronous generator using a feedback proportional-integral (PI) controller to meet aircraft standards [10]. The capacitor $C_{d}$ at the output of the TRU in Fig. 2 is for smoothing purposes.

Three types of DC loads are connected to the regulated 270-VDC bus through different DC/DC converters as shown

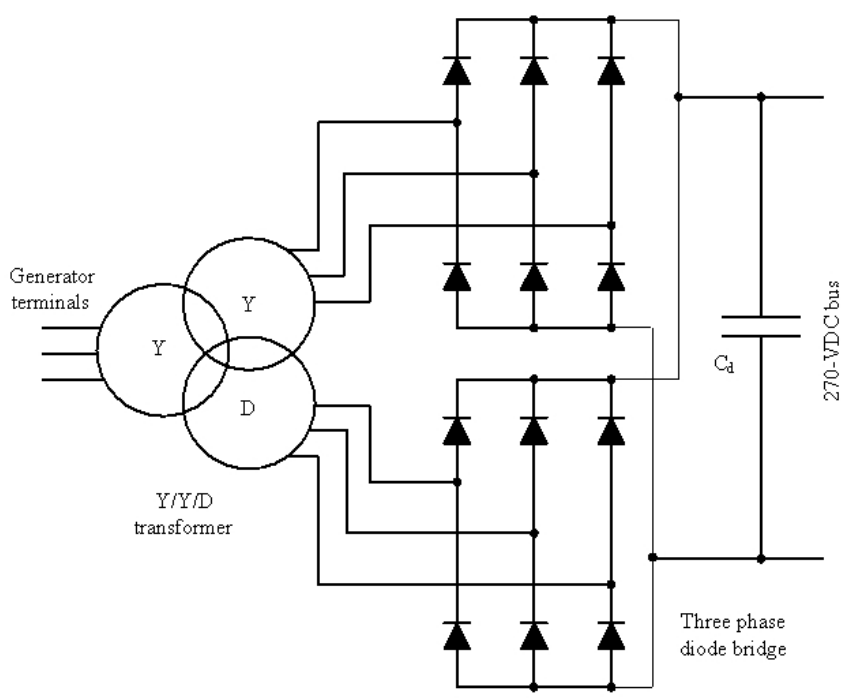

Fig. 2. The 12-pulse transformer rectifier unit.

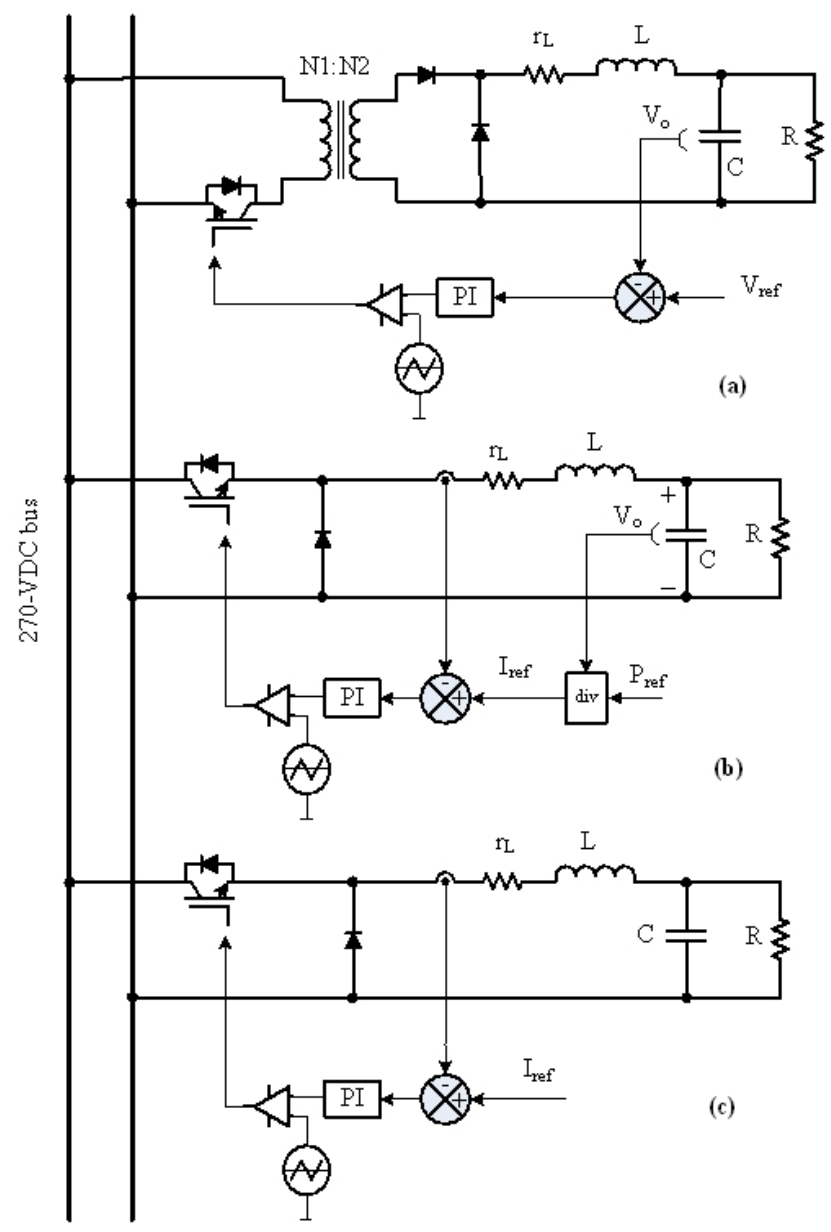

Fig. 3. Controlled DC loads connected at the 270-VDC bus: (a) CV, (b) $\mathrm{CP}$, (c) CC loads.

in Fig. 3. These loads are classified as; a constant power (CP) load of $10-\mathrm{kW}$, a constant current (CC) load of 100-A, 20-kW and a constant voltage (CV) load of $28-\mathrm{VDC}, 5.6-\mathrm{kW}$. The DC loads are regulated using PI controllers. All of the used $\mathrm{DC} / \mathrm{DC}$ converters are of the conventional type which contains 
TABLE I

AC LOAD PARAMETERS OF THE AIRCRAFT POWER SYSTEM

\begin{tabular}{|c|c|c|c|c|c|}
\hline Load & $\mathrm{S}(\mathrm{VA})$ & $\mathrm{R}(\Omega)$ & $\mathrm{L}(\mathrm{mH})$ & $\mathrm{PF}$ & $\mathrm{I}(\mathrm{A})$ \\
\hline $\mathrm{A}$ & 18000 & 2.0 & 0.4 & 0.9 & 52.0 \\
\hline $\mathrm{B}$ & 2800 & 14.0 & 2.8 & 0.9 & 8.0 \\
\hline $\mathrm{C}$ & 15500 & 2.3 & 0.5 & 0.87 & 45.0 \\
\hline $\mathrm{M}_{1}$ & \multicolumn{5}{|c|}{ Load torque $=9 \mathrm{Nm}$} \\
\hline $\mathrm{M}_{2}$ & \multicolumn{5}{|c|}{ Load torque $=6 \mathrm{Nm}$} \\
\hline $\mathrm{M}_{3}$ & \multicolumn{5}{c|}{$=4 \mathrm{Nm}$} \\
\hline
\end{tabular}

only one IGBT switch, see Fig. 3.

To provide a constant frequency of $400-\mathrm{Hz}$ at a $200-\mathrm{VAC}$ load bus a 12-pulse sinusoidal PWM inverter is used. The 12-pulse inverter consists of two series connected 6-pulse IGBT inverters as shown in Fig. 4. The 12-pulse inverter is controlled using a PI controller to provide the required voltage magnitude, $200-\mathrm{V}$, and frequency, $400-\mathrm{Hz}$, at the $\mathrm{AC}$ load bus. The rms phase output voltage, $V_{p h}$, of a sinusoidal PWM inverter is given in terms of its DC voltage $V_{d}$ and the modulation index $m$ [11] is given as:

$$
V_{p h}=0.5 \times m \times V_{d} / \sqrt{2} .
$$

The output voltage would have a 12-pulse waveform, with harmonics of the order as:

$$
h=k p \pm 1, V_{h}=V_{1} / h
$$

where $h$ is the characteristic harmonic order, $k$ is a constant, $p$ is the converter pulse number $(=12), V_{h}$ is the harmonic voltage and $V_{1}$ is the fundamental voltage component.

One of the important methods to evaluate the power quality of a power system is to calculate the Total Harmonic Distortion (THD) factor. The THD is calculated as:

$$
T H D=\sqrt{v_{r m s}^{2}-V_{1}^{2}} / V_{1}
$$

where $V_{r m s}$ is the total rms voltage.

Two different kinds of AC loads are used in the simulated aircraft electric power system. The first type is passive AC loads consisting of a series RL load with a PF not less than 0.85 as recommended by aircraft standards [10]. These loads are named A, B, and C as shown in Fig. 5. The other type is dynamic loads consisting of three different rating induction motors of $11.2-\mathrm{kW}, 7.5-\mathrm{kW}$ and $5.0-\mathrm{kW}$, which commonly exist [12] on aircraft for electro-hydrostatic actuation and/or electro-mechanical actuation. They are connected to the 400$\mathrm{Hz} 200$-VAC bus and named $\mathrm{M}_{1}, \mathrm{M}_{2}$ and $\mathrm{M}_{3}$, see Fig. 5. Both static and dynamic AC loads parameters are listed in Table I. The motors are loaded with a constant torque load. It is worth mentioning that the inverter-output passive filter is connected at the 200-VAC, $400-\mathrm{Hz}$ load bus to mitigate the harmonics generated from the 12-pulse PWM inverter.

\section{AIRCRAFT ELECTRIC POWER SYSTEM SIMULATION WITHOUT HARMONIC FILTERS}

The aircraft electric power system shown in Fig. 1 is simulated using the PSIM8 software package. The generator speed is controlled to provide a continuous frequency range

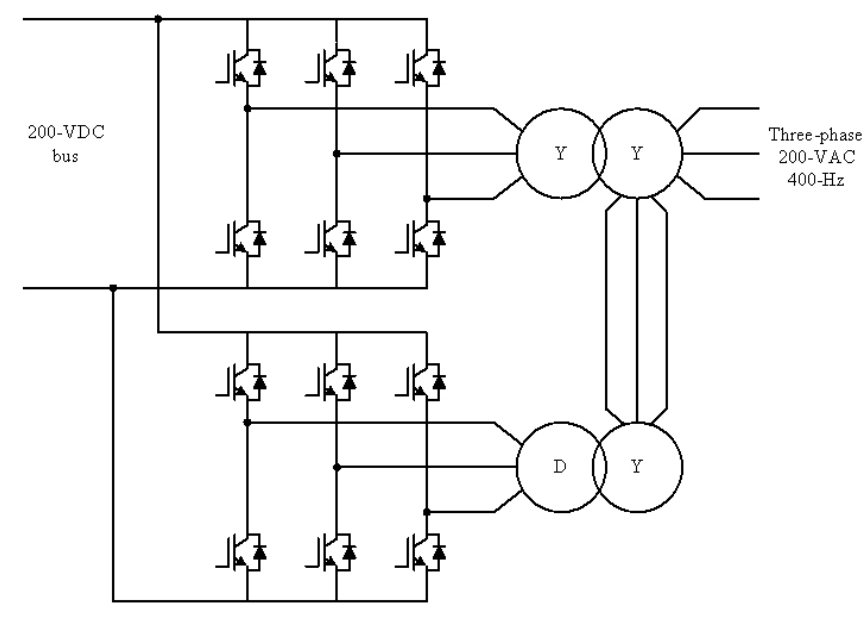

Fig. 4. The 12-pulse inverter configuration.

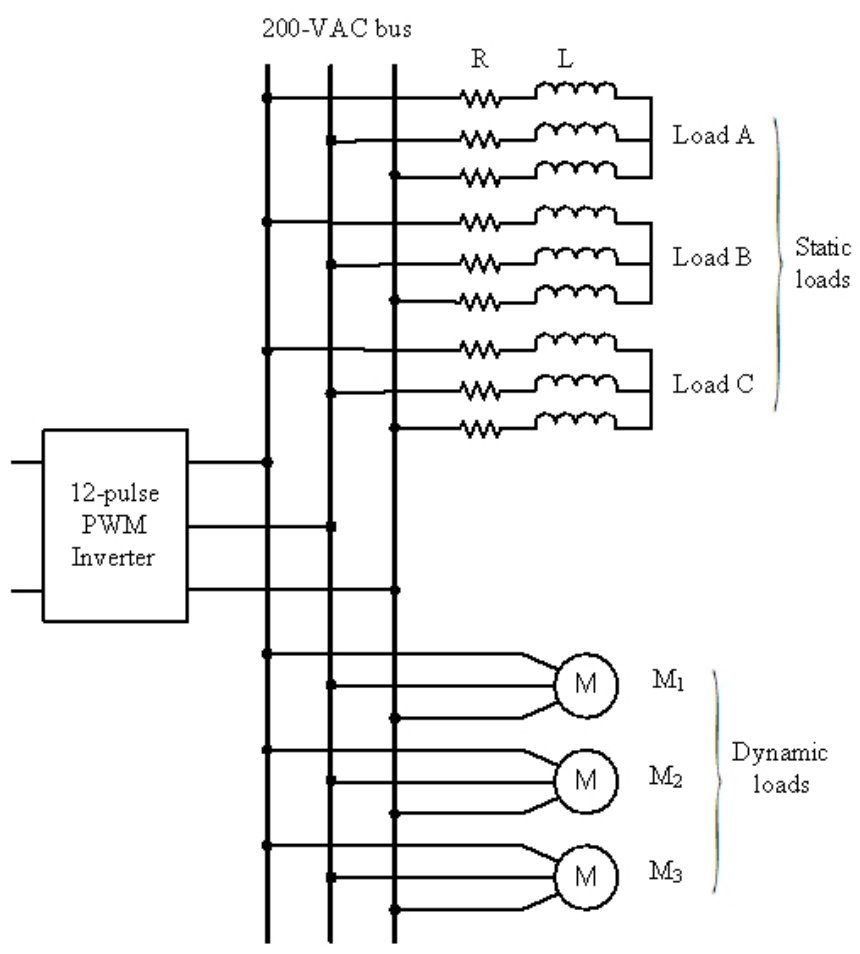

Fig. 5. Considered static and dynamic AC loads connected at the 200-VAC load bus.

from $360-800-\mathrm{Hz}$. The aircraft generating system is loaded with different loading scenarios as listed in Table II at different percentages of full load. The passive (A, B, C), dynamic $\left(\mathrm{M}_{1}\right.$, $\mathrm{M}_{2}, \mathrm{M}_{3}$ ) and DC (CP, CC, CV) loads are switched according to each case-study. For each case-study the THD values of the voltage and current are calculated at the generator terminals and at the AC load bus.

Fig. 6 and 7 show the THDv and THDi of the generator voltage and current for case-study 1 to case-study 7 (cs1cs7) as influenced by the operation frequencies. The THDv is always greater than $5 \%$ for all cases over the entire frequency range and goes as high as $12 \%$ for case-study 7 , see Fig. 6 . For higher loads (cs4-cs7), the THDv is higher than it is for light 
TABLE II

LOADING SCENARIOS

\begin{tabular}{|c|c|c|c|c|}
\hline Case No. & Passive loads & Dynamic loads & DC loads & \% of full load \\
\hline 1 & & $\mathrm{x}$ & & $25 \%$ \\
\hline 2 & $\mathrm{x}$ & & & $35 \%$ \\
\hline 3 & & & $\mathrm{x}$ & $40 \%$ \\
\hline 4 & $\mathrm{x}$ & $\mathrm{x}$ & & $60 \%$ \\
\hline 5 & & $\mathrm{x}$ & $\mathrm{x}$ & $65 \%$ \\
\hline 6 & $\mathrm{x}$ & & $\mathrm{x}$ & $75 \%$ \\
\hline 7 & $\mathrm{x}$ & $\mathrm{x}$ & $\mathrm{x}$ & $100 \%$ \\
\hline
\end{tabular}

loads (cs1-cs3). The opposite is true for the generator current THDi. For larger loads, the THDi reaches the standard limit of 5\%, see Fig. 7. At higher loads cases, the THDi values comply with standards.

The power factor (PF) at the generator terminals of the aircraft electric power system for case-study No. 1 to casestudy No. 7 are shown in Fig. 8 as determined by the operation frequency. Higher PF values are recorded for case-study No. 3 where only DC loads are applied to the system. The lowest PF values are for case-study No. 4 where the AC passive and dynamic loads are applied and case-study No. 7 where all of the loads are applied. For all of the case-studies the PF of the generator is higher than the standard limit of 0.85 [10].

\section{PASSIVE POWER FILTER DESIGN}

When static capacitors are connected to a system for voltage or reactive power control, there is a frequency at which the capacitors are in parallel resonance with the power system inductive reactance. It is found that the filter capacitance $C_{f}$ should be less than $90-\mu \mathrm{F}$ to avoid resonance with the aircraft electric system. The parallel resonant frequency $\left(f_{p}\right)$ can be calculated as [13]:

$$
f_{p}=f_{1} \sqrt{\frac{M V A_{s c}}{M \operatorname{var}_{c}}}=f_{1} \sqrt{\frac{X_{c}}{X_{s}}}=\frac{1}{2 \pi} \sqrt{\frac{1}{L_{s} C_{f}}}
$$

where $\mathrm{MVA}_{s c}$ is the short circuit level at the point of study, $\mathrm{Mvar}_{c}$ and $\mathrm{X}_{c}$ are the capacitor filter rating and its reactance, $\mathrm{X}_{s}$ is the reactance of the power system up to the filter location, $\mathrm{L}_{s}$ is the corresponding inductance and $f_{1}$ is the fundamental operation frequency which changes from 400-to 800-Hz.

The HPF design is based on an iterative routine which chooses the filter parameters based on two criteria; the filter losses which are to be kept at a minimum at the fundamental frequency and the THD values of the generator waveforms which are reasonable and comparable to the standard values. Three different passive filters, as shown in Fig. 9, are used to improve the aircraft power quality. Two of them will be connected at the generator terminals one at a time, Fig. 9 (a) and (b), and the other will be connected all the time at the output of the 12-pulse inverter at the 200-VAC load bus, Fig. $9(c)$.

\section{A. First-Order High-Pass Filter (RC Type)}

The first-order HPF is the simplest high-pass harmonic filter. It consists of a capacitor with a series resistance per phase as shown in Fig. 9 (a). The value of the capacitance is chosen

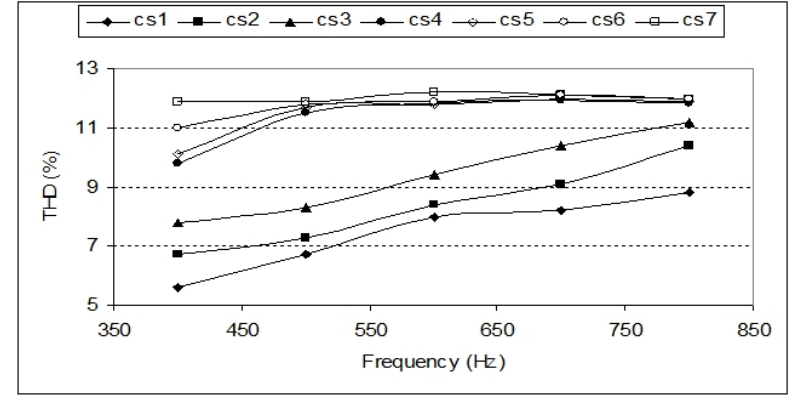

Fig. 6. Generator voltage THDv as function of the operation frequency for different case studies.

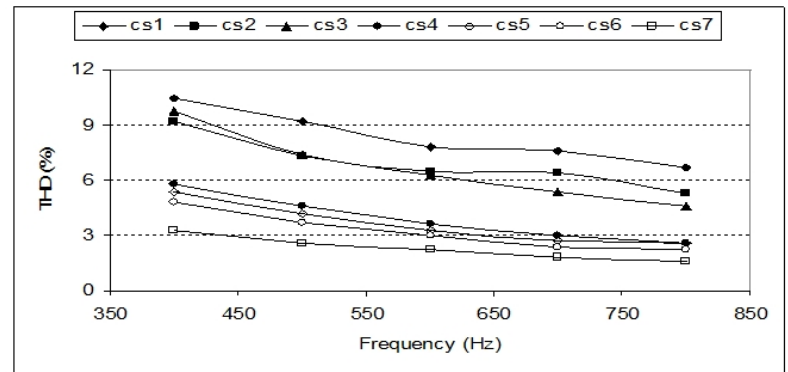

Fig. 7. Generator current THDi as function of the operation frequency for different case studies.

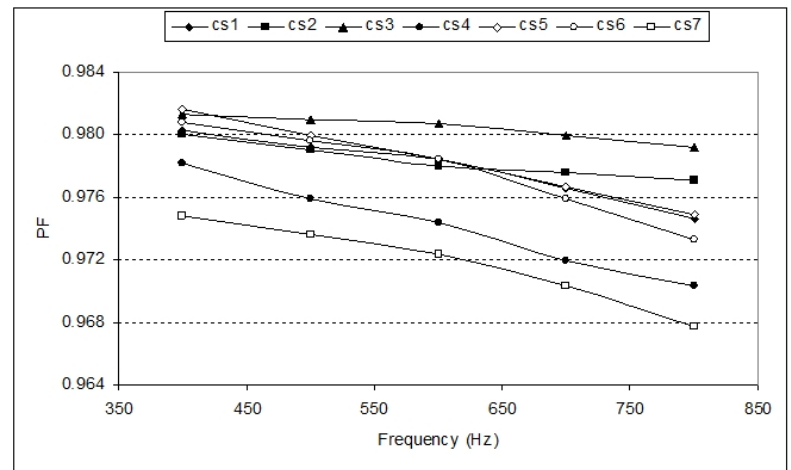

Fig. 8. Generator PF as a function of operation frequency for different case-studies.

to avoid a parallel resonance with the aircraft power system on the one hand and to keep the THD values at the generator terminals as low as possible on the other. The series resistance is calculated from the filter corner frequency and chosen to keep the filter losses at a minimum in the fundamental frequency range (400-800-Hz). Three different corner frequencies are chosen and the THD for the generator voltage and current as well as the filter losses at the fundamental frequency are calculated and compared to choose the best design.

The filter capacitance $C_{f}$ is calculated from the filterinjected reactive power per phase, $Q_{c}$ as [14]:

$$
C_{f}=G_{c} /\left(\omega_{1} V_{1}^{2}\right)
$$

where $\omega_{1}$ is the fundamental frequency $(\mathrm{rad} / \mathrm{s})$.

The filter provides a low impedance above a corner frequency to filter out the high-frequency harmonics. The filter 

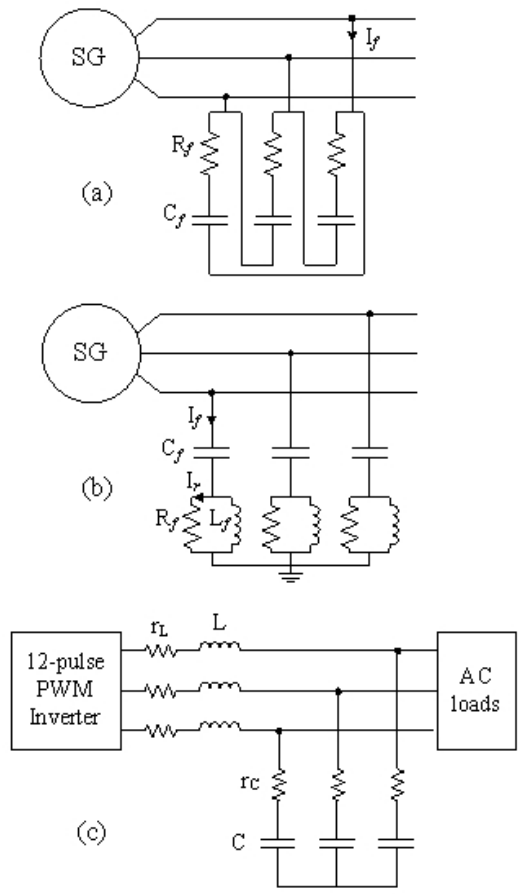

Fig. 9. Designed passive filters: (a) first-order, (b) second-order and (c) inverter-output filter.

TABLE III

FIRST-ORDER HPF CHARACTERISTIC AND PARAMETERS

\begin{tabular}{|c|c|c|c|}
\hline \multirow{3}{*}{ Filter parameter } & \multicolumn{3}{|c|}{ Corner frequency } \\
\cline { 2 - 4 } & $f_{c 1}$ & $f_{c 2}$ & $f_{c 3}$ \\
& $(4400 \mathrm{~Hz})$ & $(6600 \mathrm{~Hz})$ & $(8800 \mathrm{~Hz})$ \\
\hline$R_{f}$ & $1.0 \Omega$ & $0.7 \Omega$ & $0.5 \Omega$ \\
\hline$C_{f}$ & \multicolumn{3}{|c}{$35 \mu \mathrm{F}$} \\
\hline$Q_{c}$ & $3.5 \mathrm{kvar}$ \\
\hline
\end{tabular}

resistance $R_{f}$ can be calculated from the corner frequency $f_{c}$ equation [15]:

$$
f_{c}=1 /\left(2 \pi C_{f} R_{f}\right) .
$$

The filter loss $\left(P_{\text {loss }}\right)$ in the fundamental frequency range is calculated as:

$$
P_{\text {loss }}=3 I_{f}^{2} R_{f}
$$

where $I_{f}$ is the filter fundamental current component per phase.

A computer routine is used to choose the filter parameters. The routine is shown in Fig. 10. The design parameters of the high pass RC filter are listed in Table III for the three selected corner frequencies.

The filter losses dependent on the operation frequency are shown in Fig. 11 for the selected three corner frequencies $\left(f_{c 1}, f_{c 2}, f_{c 3}\right)$. To improve system efficiency, the filter losses should be at the minimum values that conform to the filter design corresponding to $f_{c 3}$. For this design, the losses at $400-\mathrm{Hz}$ are equal to $460-\mathrm{W}$ ( $0.5 \%$ of the generator power) compared with $1900-\mathrm{W}(2.0 \%$ of the generator power) at 800 Hz.

The THDv values of the generator voltage at different frequencies for the three selected corner frequencies are shown

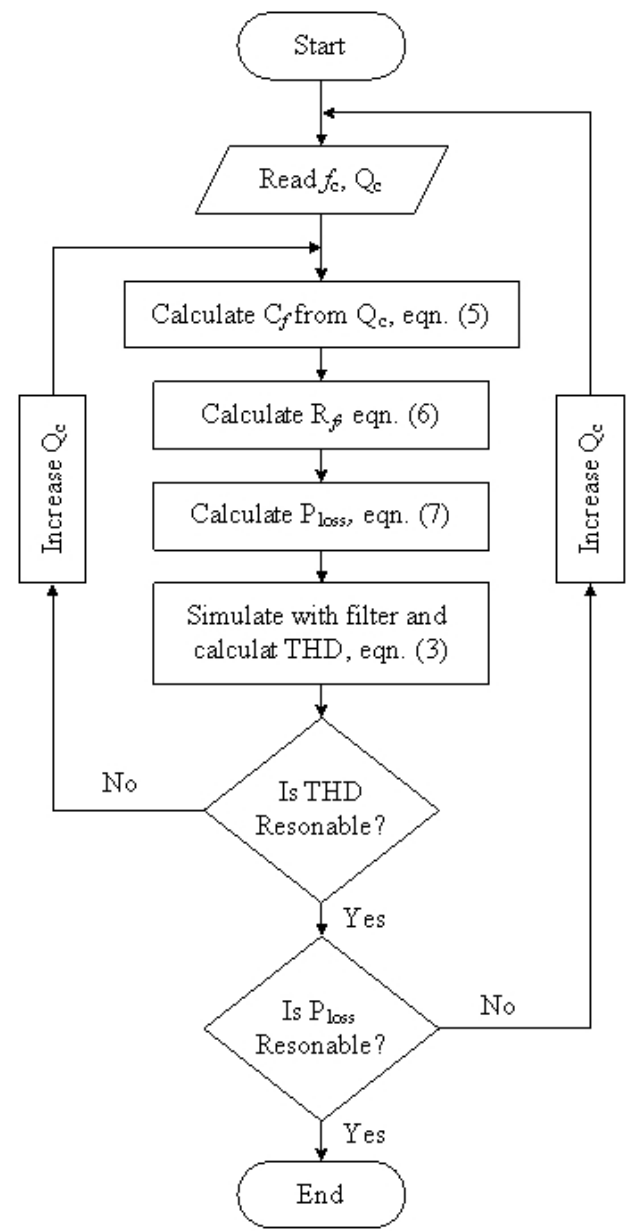

Fig. 10. Flow chart of the filter design procedure steps.

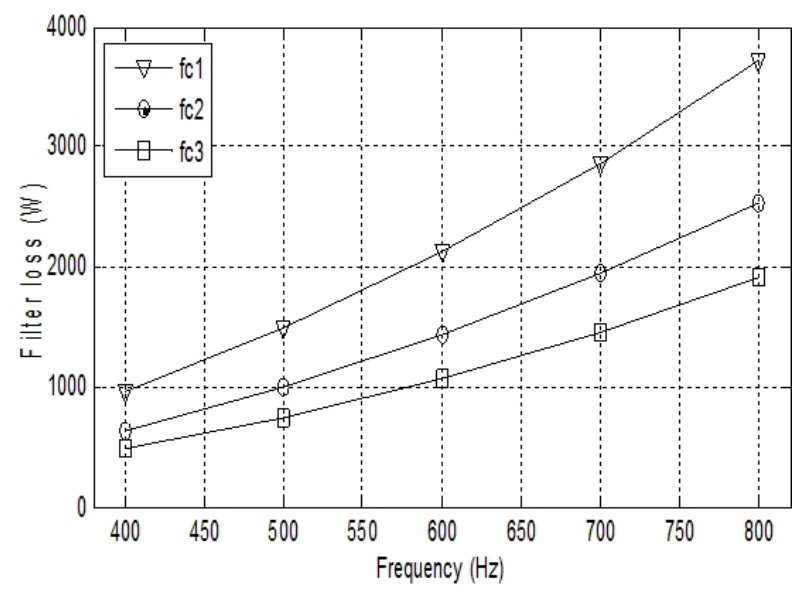

Fig. 11. First-order harmonic filter losses as function of operation frequency at different corner Frequencies.

in Fig. 12. The THDv value at $400-\mathrm{Hz}$ is slightly larger for $f_{c 3}$ and lower for most of the frequency range when compared to $f_{c 1}$ and $f_{c 2}$. The normal operation of an aircraft is at $400-\mathrm{Hz}$ and it only goes to higher speeds under abnormal conditions such as faults, the changing/replacing of a load supply or cruising operation. Therefore a first-order HPF is rarely used due to its large power losses at the fundamental frequency, Fig. 11. 


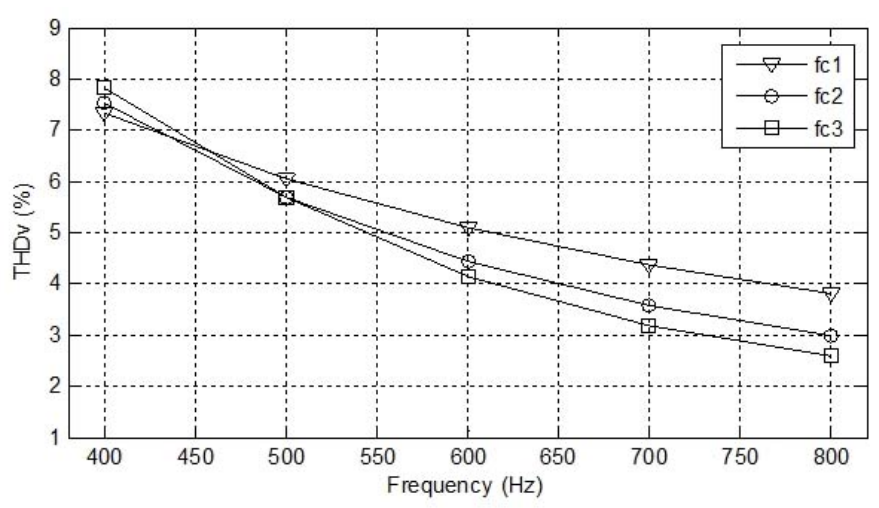

Fig. 12. Generator THDv values as function of the frequency at different corner frequencies for RC filter case.

\section{B. Second-Order High-Pass Filter (RLC Type)}

The second-order HPF is the simplest to apply while providing good filtering action and reduced losses at the fundamental frequency. Typical values of the quality factor, $\mathrm{Q}$ for a high pass filter, vary from 0.5 to 2.0. With a high $Q$, the filtering action is more pronounced at the corner frequency, while at higher frequencies the filter impedance rises steadily. For lower values of $\mathrm{Q}$, the response at the corner frequency is not noticeable, and as the frequency increases, the impedance is roughly constant. The configuration of a second-order HPF is shown in Fig. 9 (b). The same procedure as the first-order filter is adopted here for determining the second-order filter parameters. Assuming the quality factor equals unity, the filter inductance, $L_{f}$ and the filter resistance $R_{f}$ of the second-order HPF are calculated as [16]:

$$
Q=R_{f} /\left(\omega_{c} L_{f}\right)
$$

where $\omega_{c}$ is the corner frequency in rad/s. The filter inductance is calculated from:

$$
\omega_{c}=1 / \sqrt{L_{f} C_{f}}
$$

where the filter capacitance $C_{f}$ is calculated in the same way as the first-order filter using (5). With the filter inductor core losses taken to be approximately equal to the winding copper losses and ignoring any capacitor leakage losses, the total filter losses can be calculated as:

$$
P_{\text {loss }}=3 I_{r}^{2} R_{f}
$$

where $I_{r}$ is the current through the equivalent filter resistance $R_{f}$, see Fig. 9 (b).

The parameters of the designed second-order HPF are listed in Table IV. The second-order HPF losses as influenced by the fundamental frequency are shown in Fig. 13. Comparing Figs. 11 and 13, the losses of the second-order HPF are much smaller than those of the first-order filter. The maximum filter loss at $800-\mathrm{Hz}$ is less than $0.06 \%$ of the generator's output power. Over the entire frequency range, the impedance of the filter inductor is approximately one-tenth of the filter resistance. Therefore, most of the shunt current passes through
TABLE IV

SECOND-ORDER HPF DESIGN PARAMETERS

\begin{tabular}{|c|c|c|c|c|}
\hline$R_{f}$ & $L_{f}$ & $C_{f}$ & $f_{c}$ & $\mathrm{Q}$ \\
\hline $0.9 \Omega$ & $32.7 \mu \mathrm{H}$ & $40.0 \mu \mathrm{F}$ & $4400 \mathrm{~Hz}$ & 1.0 \\
\hline
\end{tabular}

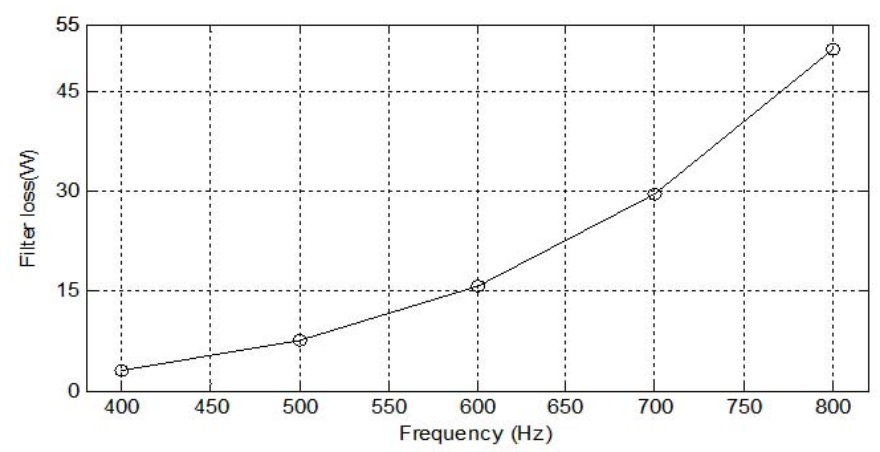

Fig. 13. The second-order harmonic filter losses at variable frequency operation.
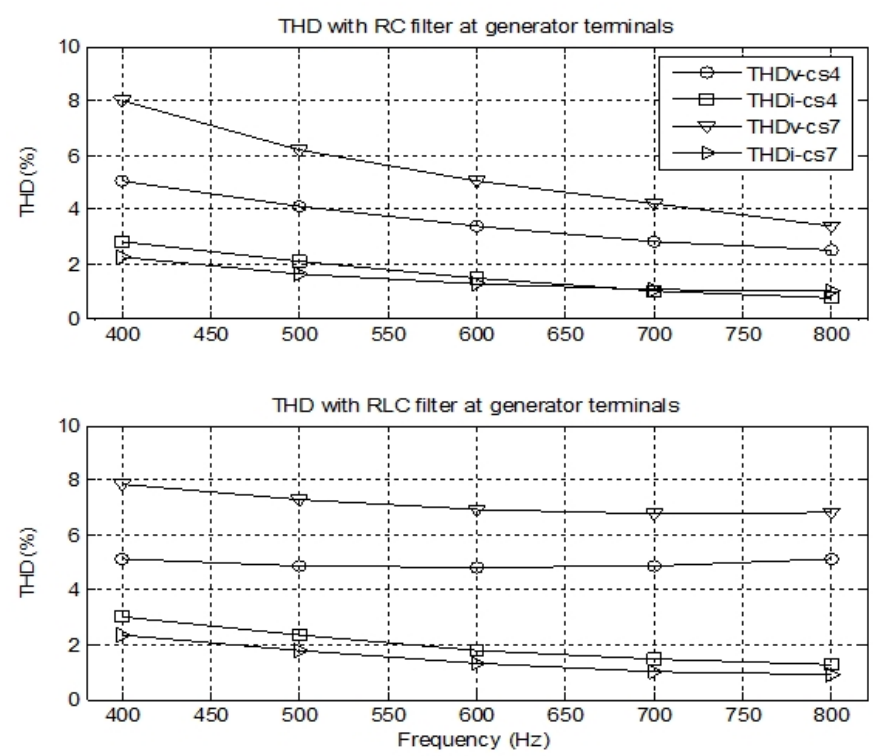

Fig. 14. THD values of generator voltage and current with RC and RLC filters for cs 4 and cs7.

the inductance with a subsequent decrease in the losses when compared with the first-order filter, see Fig. 9 (b). The choice between first and second order harmonic filters is based solely on technical merits as well as cost and sophistication.

\section{Inverter-Output Filter Design}

The design of an output filter for a sinusoidal pulse width modulation (SPWM) inverter can be an extensive process that often involves an analysis of the inverter output voltage and the load current considering nonlinear loads [17],[18]. The proper design of a 12-pulse SPWM inverter output filter is crucial in order to supply near sinusoidal voltage to sensitive loads connected to an aircraft electric power system. A major design criterion is the selection of a filter cut-off frequency. The cutoff frequency has to fall between the highest fundamental frequency of the SPWM inverter switching frequency with a significant attenuation at the high frequency and a minimum 
attenuation as well as a minimum phase-lag within the operating range of the frequency.

The inverter output passive filter simulated in this study is an ordinary LC high pass filter connected between the three phases and the neutral. The filter parameters are selected to provide a minimum attenuation and phase lag within the frequency range of operation and a maximum attenuation at the high frequency near the inverter switching frequency. The filter inductor has an inductance of $40-\mu \mathrm{H}$ with a series resistance of 0.04- $\Omega$ and the shunt capacitor has capacitance of $0.2-\mathrm{mF}$ with a series resistance of $0.02-\Omega$, see Fig. 9 (c). The filter proved to be efficient in mitigating the harmonics generated from the 12-pulse sinusoidal PWM inverter to within the values required by the harmonics standards.

\section{AIRCRAFT POWER SYSTEM PERFORMANCE WITH HARMONIC FILTERS}

To study the effectiveness of the first-order (RC) and second-order (RLC)passive filters, either of the two filters is connected at the generator terminals and each time the THD of the voltage and current for case-studies No. 4 and 7 are calculated at different operation frequencies and plotted in Fig. 14. The THD of the generator current for both cases is always less than 5\%. At higher frequency values, the THD of the generator voltage is less than $5 \%$ for RC filter while the THD values are almost constant for RLC filter and greater than 5\% for case-study No. 7.

Comparing Figs. 6 and 7 with Fig. 14, the THD values of the generator voltage and the current are lower and reach the standard values for most case studies with the installation of either RC or RLC filters at the generator terminals under variable speed conditions. The THDv and the THDi of the 200-VAC bus with the installation of either the RC or RLC filters at the generator terminals are always less than $5 \%$ as shown in Fig. 15 for case-studies No. 4 and 7. The inverteroutput filter reduces the 12-pulse inverter harmonics to less than the standard limit of $5 \%$.

The PF at the generator terminals being dependent on the operation frequency after the installation of either the RC or RLC filters is shown in Fig. 16 for case-studies No. 4 and 7. With the RC filter the PF is slightly higher than that of the RLC filter. With the RC filter, the capacitor works as a power factor correction in addition to its filtering action. In the RLC filter the inductance equalizes some of the capacitive reactance. Compared with Fig. 8, the PF is higher for both filters than the case without them. From Fig. 16, one should note that the increase in the PF with the increase in the operation frequency is attributed to the decrease of the capacitive reactance of the filter capacitor.

Time waveforms for the aircraft electric power system are shown in Fig. 17 for the RC passive filter case at 400$\mathrm{Hz}$ operation and the full load condition. In this figure, the generator voltage $\left(V_{G}\right)$ and current $\left(I_{G}\right)$ waveforms, the main AC load bus voltage $\left(V_{L}\right)$ and current $\left(I_{L}\right)$ waveforms, the RC filter current $\left(I_{f}\right)$ waveform, and the main 270-VDC bus regulated voltage $\left(V_{d}\right)$ are demonstrated. For the RLC passive filter case, the time waveforms are shown in Fig. 18. The new
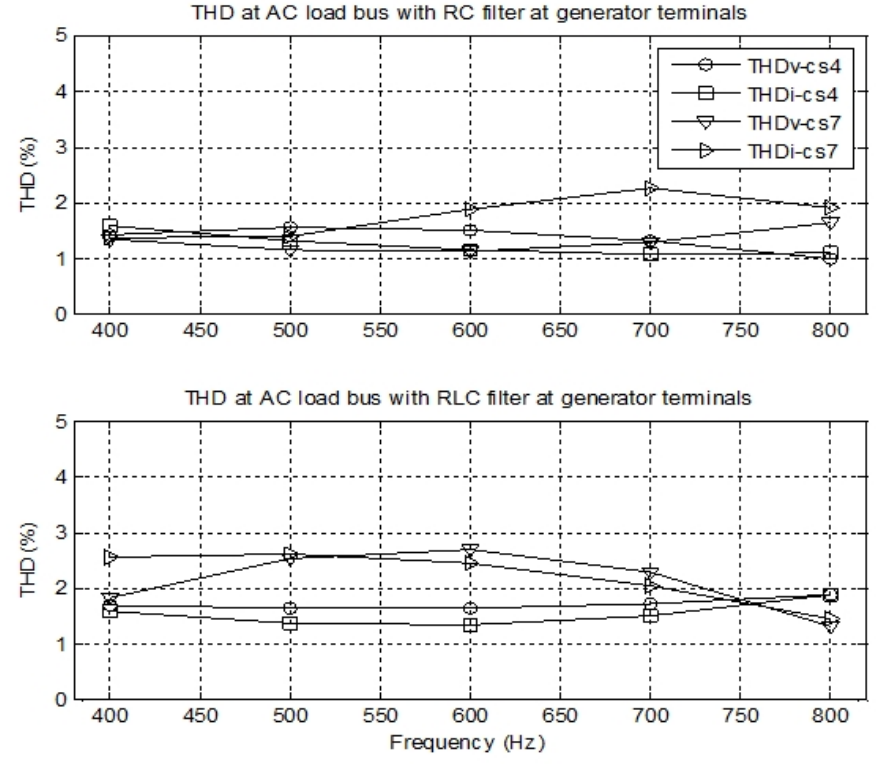

Fig. 15. THD values of the AC load bus voltage and current with RC and RLC filters for case-studies No. 4 and 7.

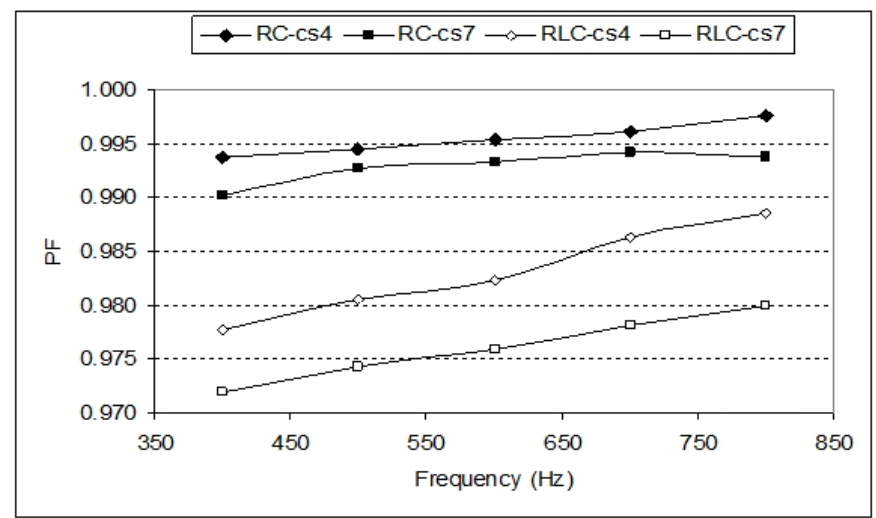

Fig. 16. Power factor at generator terminals as function of the frequency for cs4 and cs7 when installing RC or RLC filters.

waveform is for the filter resistance current $\left(I_{r}\right)$, see Fig. 9 (b). The passive HPFs help in reducing the THD values to the standard values.

\section{MEETING AIRCRAFT ELECTRIC STANDARDS}

The aircraft electric standards [20] establish the requirements and characteristics of aircraft electric power systems provided at the input terminals of electric utilization equipment. The three phase $200 \mathrm{~V}$-AC line voltage at load terminals should comply with the aircraft standards regarding its steady state, unbalance, modulation, phase difference, crest factor and DC component.

These parameters are listed in Table $\mathrm{V}$ with the simulation results of the studied aircraft system under the most severe load (case-study No. 7) for different values of the operation frequency. Table $\mathrm{V}$ confirms that the studied aircraft electric system characteristics are within the standards limits for all of the frequency range. The 12-pulse sinusoidal PWM 
TABLE V

AIRCRAFT 200-VAC NORMAL OPERATION CHARACTERISTICS

\begin{tabular}{|c|c|c|c|c|c|c|}
\hline parameter & \multirow{2}{*}{ Standard [10] } & \multicolumn{5}{|c|}{ Frequency $(\mathrm{Hz})$} \\
\cline { 3 - 7 } & & 400 & 500 & 600 & 700 & 800 \\
\hline Steady state voltage & $108-118 \mathrm{~V}$ & 115.5 & 115.1 & 115.3 & 114.7 & 114.9 \\
\hline Voltage unbalance & $3 \mathrm{~V}$ & 1.35 & 0.13 & 0.09 & 0.51 & 0.14 \\
\hline Voltage modulation & $2.5 \mathrm{~V}$ & 1.16 & 1.76 & 1.13 & 1.25 & 1.50 \\
\hline Phase voltage difference & $116^{\circ}-124^{\circ}$ & 120.5 & 120.8 & 120.2 & 120.1 & 119.5 \\
\hline Crest factor & $1.31-1.51$ & 1.44 & 1.46 & 1.43 & 1.44 & 1.46 \\
\hline DC component & $\pm 0.1 \mathrm{~V}$ & 0.02 & 0.02 & 0.04 & 0.03 & 0.06 \\
\hline
\end{tabular}

TABLE VI

AIRCRAFT 28-VDC NORMAL OPERATION CHARACTERISTICS

\begin{tabular}{|c|c|c|c|c|c|c|}
\hline parameter & Standard [10] & \multicolumn{5}{|c|}{ Frequency (Hz) } \\
\cline { 3 - 7 } & & 400 & 500 & 600 & 700 & 800 \\
\hline Steady state voltage & $22.0-29.0 \mathrm{~V}$ & 28.0 & 28.0 & 28.0 & 28.0 & 28.0 \\
\hline Distortion factor & $0.035 \mathrm{max}$ & 0.0032 & 0.003 & 0.0032 & 0.0034 & 0.0032 \\
\hline Ripple amplitude & $1.5 \mathrm{~V}$ max & 0.050 & 0.032 & 0.035 & 0.037 & 0.032 \\
\hline
\end{tabular}

TABLE VII

AIRCRAFT 270V-DC NORMAL OPERATION CHARACTERISTICS

\begin{tabular}{|c|c|c|c|c|c|c|}
\hline parameter & Standard [10] & \multicolumn{5}{|c|}{ Frequency $(\mathrm{Hz})$} \\
\cline { 3 - 7 } & & 400 & 500 & 600 & 700 & 800 \\
\hline Steady state voltage & $250-280 \mathrm{~V}$ & 270.3 & 270.3 & 270.4 & 270.6 & 270.9 \\
\hline Distortion factor & 0.015 & 0.004 & 0.004 & 0.003 & 0.004 & 0.003 \\
\hline Ripple amplitude & $6.0 \mathrm{~V}$ & 3.70 & 3.90 & 3.60 & 4.16 & 3.38 \\
\hline
\end{tabular}

inverter along with the inverter output passive filter reduces the harmonics to a minimum at the 200-VAC bus. The aircraft standards [10] define the required parameters for the 28-VDC bus. These characteristics are listed in Table VI with the simulation results of the studied aircraft system at different frequencies. The 270-VDC bus characteristic parameters are listed in Table VII with the simulation results at different frequencies.

\section{CONCLUSIONS}

The VSCF aircraft electric power system is modeled and analyzed under variable-speed constant-frequency operation.
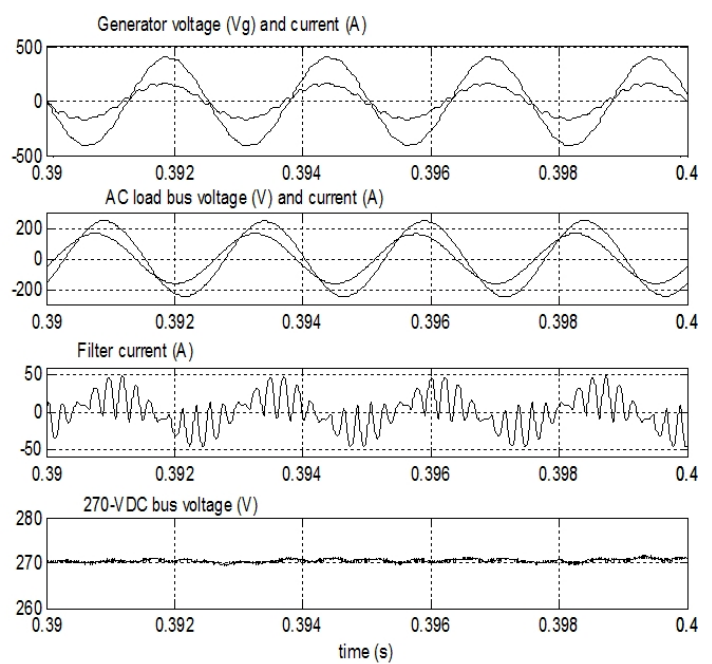

Fig. 17. Generator voltage and current, AC load voltage and current, filter current and $270-\mathrm{VDC}$ bus voltage at $400-\mathrm{Hz}$ with RC filter for case-study No. 7.
The modeled aircraft system is studied in the frequency range of $400-800-\mathrm{Hz}$ for different loading scenarios including passive and dynamic AC loads in addition to nonlinear DC loads of constant power, constant current, and constant voltage. The power quality characteristics of the modeled system are generated and analyzed. First-order and secondorder high-pass filters are designed to reduce the harmonics at the generator terminals so that they are lower than the standard values. The power quality of the studied aircraft
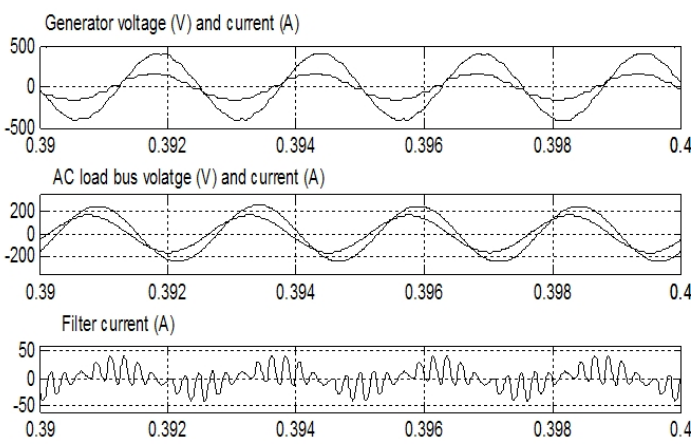

Filter resistance current (A)
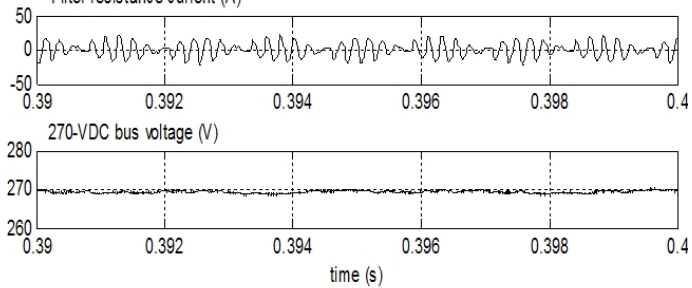

Fig. 18. Generator, AC load voltages and currents, total filter current, filter resistive current and 270 -VDC bus voltage at $400-\mathrm{Hz}$ with RLC filter for case-study No. 7. 
electric system complies with the rigorous aircraft electrical standard MIL-STD-704F for 200-VAC systems in regards to the steady state magnitude, the unbalance, the modulation, the crest factor and DC component. Moreover, the power quality of the modeled aircraft system complies with the established standards for both 28-VDC and 270-VDC voltage systems in regards to the steady state magnitude, the distortion factor, and the ripple amplitudes.

\section{REFERENCES}

[1] J.A. Rosero, J.A. Ortega, E. Aldabas and L. Romeral, "Moving towards a more electric aircraft," IEEE Aerosp. Electron. Syst. Magazine, Vol. 22, Issue 3, pp. 3-9, Mar. 2007.

[2] K.W.E. Cheng, "Comparative study of AC/DC converters for more electric aircraft," IEE Power Electronics and Variable Speed drives Conference, pp. 299-304, Sep. 1998.

[3] E.H.J. Pallet, Aircraft electrical systems, Pearson Prentice Hall, 1987.

[4] V.V. Vadher, I.R. Smith and S. Williams, "Mathematical modeling of a VSCF aircraft generating system," IEEE Trans. Aerosp. Electron. Syst., Vol. 22, No. 5, pp. 573 - 582, Sep. 1986.

[5] J. Sun, M. Chen and K.J. Karimi, "Aircraft power system harmonics involving single-phase PFC converters," IEEE Trans. Aerosp. Electron. Syst., Vol. 44, No. 1, pp. 217-226, Jan. 2008.

[6] A. Eid, M. Abdel-Salam, H. El-Kishky and T. El-Mohandes, "Simulation and transient analysis of conventional and advanced aircraft electric power systems with harmonics mitigation," Electric Power Systems Research, Vol. 79, Issue 4, pp. 660-680, Apr. 2009.

[7] G. Guanghai, M. Heldwein, U. Drofenik, J. Minibock, K. Mino and J. Kolar, "Comparative evaluation of three phase high power factor ACDC converter concepts for application in future more electric aircraft," IEEE Trans. Ind. Electron., Vol. 52, No. 3, pp. 727-737, Jun. 2005.

[8] A. Eid, M. Abdel-Salam, H. El-Kishky and T. El-Mohandes, "Active power filters for harmonic cancellation in conventional and advanced aircraft electric power systems," Electric Power Systems Research, Vol. 79, Issue 1, pp. 80-88, Jan. 2009.

[9] I. Moir and A. Seabridge, Aircraft systems: mechanical, electrical, and avionics; subsystem integration, American Institute of Aeronautics and Astronautics, Inc., 2001.

[10] “MIL-STD-704F” Aircraft electric power characteristics, Military Standard, 2004.

[11] B.K. Bose, Modern power electronics and AC drives, Prentice-Hall, Inc., 2002.

[12] Chandrasekaran, S., Lindner, D.K., Boroyevich, D., "Analysis of subsystem integration in aircraft power distribution systems," IEEE International Symposium on Circuits and Systems, Vol. 5, pp. 82-85, 1999.

[13] IEEE recommended practices and requirements for harmonic control in electrical power system, ANSI/IEEE Std. 519- 1992.

[14] H.L. Ginn, and L.S. Czarnecki, "An optimization based method for selection of resonant harmonic filter branch parameters," IEEE Trans. Power Delivery, Vol. 21, No. 3, pp. 1445-1451, Jul. 2006.

[15] C.-J. Wu, J.-C. Chiag, Ching-Jung Liao and Jin-Shyr Yang, "Investigation and mitigation of harmonic amplification problems caused by single-tuned filters," IEEE Trans. Power Delivery, Vol. 13, No. 3, pp. 800-806, Jul. 1998.

[16] J. C. Das, "Passive filters-potentialities and limitations," IEEE Trans. Ind. Appl., Vol. 40, No. 1, pp. 232-241, Feb. 2004.

[17] T.G. Habetler,R. Naik and T.A. Nondahl, "Design and implementation of an inverter output LC filter used for $\mathrm{dv} / \mathrm{dt}$ reduction," IEEE Transactions on Power Electronics, Vol. 17, Issue 3, pp. 327-331, Aug. 2002.

[18] Hyosung Kim and Seung-Ki Sul, "Analysis on output LC filters for PWM inverters," IEEE 6th Power Electronics and Motion Control Conference, pp. 384-389, 2009.

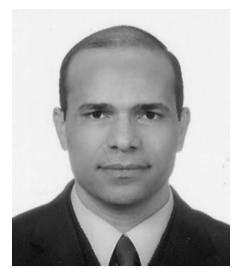

Ahmad Eid (S'06-M'10) was born in Qena, Egypt. He received his B.S. and M.S. in Electrical Engineering from Assiut University, Assiut, Egypt, in 1997 and 2002, respectively. He received his Ph.D. in Electrical Engineering from the South Valley University, Aswan, Egypt in 2010. Currently, he is with the Electrical Engineering Department, South Valley University, Aswan, Egypt. He worked in a joint research program at the University of Texas at Tyler, TX, USA from January
2008 to January 2010. He was a Research Engineer at the Malaya University, Kuala Lumpur, Malaysia, from 2003 to 2005 on a linear machine design project and with Kyungnam University, South Korea, in 2006 on a wind power generation project. His research activities include power quality, renewable energy, aircraft electric power systems, high voltage applications and linear machines.

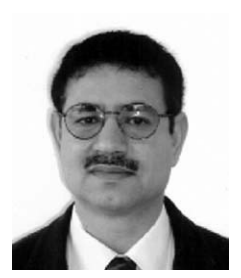

Hassan El-Kishky (SM'04) received his B.S. in Electric Power Systems and Rotating Machines from Ain Shams University, Cairo, Egypt, in 1984 and his M.S. and Ph.D. in Electrical Engineering from Assiut University, Assiut, Egypt, and Arizona State University, Tempe, AZ, in 1990 and 1995, respectively. Currently, he is an Associate Professor of Electrical Engineering at the University of Texas, Tyler. He is also a Consultant in the broad areas of electric power systems and electromagnetic interference/electromagnetic compatibility (EMI/EMC) and a Co-Founder of the National Energy Technologies, LLC, providing services in the design and analysis of electrical systems. He was the R\&D Manager at the National Electric Coil from 1997 to 1998. His areas of interest include high-voltage insulation systems for large rotating machines, stress grading, corona-suppression systems, modeling of high-voltage phenomena, power quality of electric power systems, as well as electromagnetic interference and compatibility. Dr. El-Kishky is a registered professional engineer in the State of Texas. He is also a certified EMC engineer by iNARTE.

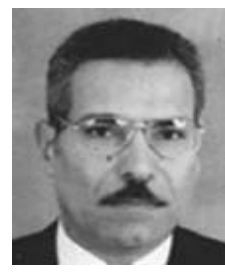

Mazen Abdel-Salam (SM'78-F'93) was born in ElMonofia, Egypt. He received his B.S., M.S., and Ph.D. in Electrical Engineering from the University of Cairo, Cairo, Egypt, in 1967, 1970, and 1973, respectively. In 1973, he joined the Faculty of Electrical Engineering, Assuit University, Assuit, Egypt, as an Assistant Professor. He became an Associate Professor in 1977. During the academic years 1977-1979, he was an Alexander von Humboldt Fellow in the Electrical Engineering Department, Technical University of Munich, Munich, Germany, and was with the Electrical Engineering Department, University of Liverpool, Liverpool, U.K. In 1979, he joined the General Electric Co., Pittsfield, MA, as a Researcher. In 1982, he rejoined Assuit University as a Professor of Electrical Power Engineering. During the academic years 1984-1994, he was a Professor of Electric Power Engineering in the Department of Electrical Engineering, King Fahd University of Petroleum and Minerals, Dhahran, Saudi Arabia. He obtained Research Fellowships at the Military Technical University of Hamburg, Germany, in 1984; the University of Leeds, U.K., in 1988; Kaiserlautern University, Germany, in 1989; Michigan Technological University, Houghton, in 1990; Toyohashi University, Japan, in 1995; the Technical University of Hamburg, Germany, in 1996; the University of Manchester, Manchester, U.K., in 2004 and 2005; and the Toyohashi University of Technology, Japan, in 2006. He was the Chairman of the Electrical Engineering Department from 1996 to 2002 and the Vice Dean for Student Affairs during 2002-2006 with the Faculty of Engineering, Assuit University. His research activities include corona studies, the digital calculation of electric fields, investigations of high-voltage phenomena, low-voltage distribution networks, control of electrical machines, and renewable energy. He is the author of High Voltage Engineering-Theory and Practice (Marcel Dekker, 2000). Dr. Abdel-Salam was the Founder/Organizer of the Middle East Power System Conference (MEPCON) held in Egypt in 1989 and continued over the years. He is a member of the Electrostatic Processes Committee of the IEEE Industrial Applications Society.

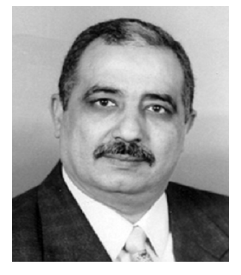

Mohamed T. El-Mohandes (M'89) was born in Egypt on March 3, 1952. He received his B.S. in Electrical Engineering, his M.S. in Electrical Power Systems Engineering, and his Ph.D. in High Voltage Engineering from Assiut University, Assiut, Egypt, in 1975, 1979, and 1986, respectively. He was a Lecturer in the Electrical Engineering Department, Assiut University, Assiut, Egypt. He was the Dean of the Faculty of Engineering, South Valley University, Aswan, Egypt. Currently, he is the Vice President for Undergraduate Affairs at South Valley University, Aswan. His current research interests include corona studies and digital calculation of electric fields. Dr. El-Mohandes has been on the Organizing Committee of the Middle East Power System Conference (MEPCON) since 1989. 